\title{
Effect of lung recruitment on blood gas index, hemodynamics, lung compliance, and rehabilitation index in children with acute respiratory distress syndrome
}

\author{
Bo $\mathrm{Li}^{1}$, Duoling $\mathrm{Li}^{2}$, Wei Huang ${ }^{3}$, Yuanyuan Che ${ }^{4}$ \\ ${ }^{1}$ Pediatric Intensive Care Unit of Maternity and Child Health Care of Zaozhuang, Zaozhuang, China; ${ }^{2}$ Pediatric Intensive Care Unit of Tongxu \\ People's Hospital, Kaifeng, China; ${ }^{3}$ Pediatric Intensive Care Unit of Zaozhuang Municipal Hospital, Zaozhuang, China; ${ }^{4}$ Department of Coronary \\ Heart Disease of Zaozhuang Municipal Hospital, Zaozhuang, China \\ Contributions: (I) Conception and design: B Li; (II) Administrative support: B Li; (III) Provision of study materials or patients: Bo Li, D Li, W Huang; \\ (IV) Collection and assembly of data: All authors; (V) Data analysis and interpretation: D Li, W Huang, Y Che; (VI) Manuscript writing: All authors; \\ (VII) Final approval of manuscript: All authors. \\ Correspondence to: Yuanyuan Che. Department of Coronary Heart Disease of Zaozhuang Municipal Hospital, 41 Longtouzhong Road, Shizhong \\ District, Zaozhuang, China. Email: cheyuanyuan2006@126.com.
}

Background: Acute respiratory distress syndrome (ARDS) is a common pediatric disease, with an increasing mortality rate in recent years. This study aims to explore the effects of lung recruitment on blood gas indexes, hemodynamics, lung compliance, and rehabilitation index in children with ARDS.

Methods: Seventy children with ARDS admitted to our hospital from December 2017 to December 2018 were selected as the study subjects, and were divided into a study group (35 cases, treated with lung recruitment strategy) and a control group (35 cases, treated with routine therapy). The changes of blood gas indexes, such as partial pressure of oxygen $\left(\mathrm{PO}_{2}\right)$, partial pressure of carbon dioxide $\left(\mathrm{PCO}_{2}\right)$, and partial pressure of oxygen/fraction of inspired oxygen $\left(\mathrm{PO}_{2} / \mathrm{FiO}_{2}\right)$ levels, as well as hemodynamic indexes, including cardiac output (CO), heart rate (HR), mean arterial pressure (MAP), central venous pressure (CVP), were compared before and after treatment in the two groups.

Results: Results showed that the difference in blood gas indexes between the two groups was statistically significant after treatment $(\mathrm{P}<0.05)$, and that the levels of $\mathrm{PaO}_{2}, \mathrm{PaCO}_{2}$, pondus Hydrogenii $(\mathrm{pH})$, and $\mathrm{PO}_{2} /$ $\mathrm{FiO}_{2}$ in the study group were all higher compared to the control group $(\mathrm{P}<0.05)$. The hemodynamic indexes showed that $\mathrm{CO}$ was significantly different between the two groups $(\mathrm{P}<0.05)$, but HR, MAP, and CVP were not $(\mathrm{P}>0.05)$. The lung compliance values of the two groups continued to increase at different time points after treatment $(\mathrm{P}<0.05)$, and the lung compliance of the study group was higher than that of the control group immediately after recruitment, as well as at 10 and $60 \mathrm{~min}$ of lung recruitment $(\mathrm{P}<0.05)$. In addition, the ventilator use, ICU stay, and hospital stay times of the study group were shorter than those in the control group $(\mathrm{P}<0.05)$, and the mortality rate of the study group was lower than that of the control group $(\mathrm{P}>0.05)$. Conclusions: The lung recruitment strategy has a significant therapeutic effect on children with ARDS. It can effectively improve blood and gas function and lung compliance, and has a positive effect on the hemodynamic stability of children with ARDS.

Keywords: Acute respiratory distress syndrome in children; lung recruitment strategy; blood gas index; hemodynamics

Submitted Oct 23, 2020. Accepted for publication Nov 28, 2020.

doi: $10.21037 / \mathrm{tp}-20-383$

View this article at: http://dx.doi.org/10.21037/tp-20-383 


\section{Introduction}

Acute respiratory distress syndrome (ARDS) is characterized by non-microcirculatory disorders, and is often accompanied by symptoms such as respiratory distress, chest tightness, and bloody sputum. In severe cases, it can lead to confusion or even death, endangering the health and lives of children (1).

Related studies have pointed out that ARDS is one of the key causes of disability and death in children, and the incidence and mortality rates of ARDS have been increasing in recent years (2). Mechanical ventilation is the main treatment method for ARDS, but it is likely to cause lung injury. Therefore, the protective lung ventilation strategy of low tide and optimal positive end-expiratory pressure is usually adopted in clinical practice, which may inevitably cause partial alveolar collapse. And the lack of lung alveolar surfactant and pulmonary hypoplasia are the main causes of ARDS in children. Recently, numerous studies have shown that the lung recruitment strategy has a significant effect on children with ARDS. This approach is based on mechanical ventilation, and can promote the reopening of alveoli through appropriate pressure to achieve the goal of oxygenation and respiratory system improvement (3). It has been reported in the literature that lung recruitment can promote the recovery of lung function in ARDS. Previous studies on lung recruitment for ARDS are mainly for adults, but the risk ARDS is higher in children, which is always caused by pulmonary hypoplasia, and different from the ARDS in adults caused by trauma, burns, major operation (4). However, there are few reports on the effect of lung recruitment strategy on blood gas index, hemodynamics, lung compliance and rehabilitation index of ARDS in children.

Herein, this study studied on 70 children hospitalized in our hospital in recent years to explore the effects of lung recruitment on blood gas indexes, hemodynamics, lung compliance, and rehabilitation index in children with ARDS, and evaluated its clinical value so as to provide a reference for the clinical treatment of ARDS. We present the following article in accordance with the CONSORT reporting checklist (available at http://dx.doi.org/10.21037/ tp-20-383).

\section{Methods}

\section{General information}

A total of 70 children with ARDS admitted to our hospital from December 2017 to December 2018 were selected as the research subjects, and were divided into a study group and a control group, with 35 cases in each group. Patients were eligible for inclusion in this study based on the following criteria: (I) patients that meet the 2019 European Respiratory Distress Syndrome Management Guidelines diagnostic criteria for pediatric ARDS, and diagnosed by CT scanning (5); (II) patients aged $<14$ years old; (III) patients with an oxygenation index (OI) $<200 \mathrm{mmHg}$; (IV) no recent use of immunomodulatory drugs; and (V) patients with complete clinical data. Patients were excluded based on the following criteria: (I) patients with severe heart, liver, kidney, and other dysfunctions; (II) patients with unstable hemodynamics; (III) patients with congenital malformations, such as congenital respiratory malformations and heart disease; (IV) patients with respiratory or multiple organ failure or shock; (V) patients with early manifestations of pulmonary hemorrhage; (VI) patients with intellectual or mental disorders who cannot cooperate with the treatment.

After selection according to the aforementioned inclusion and exclusion criteria, there were 18 males and 17 females in the study group. Patients in this group were aged 2-12 years, with an average of age of $6.68 \pm 1.80$ years old, and had a body mass index (BMI) of $16-25 \mathrm{~kg} / \mathrm{m}^{2}$, with an average BMI of $21.36 \pm 3.23 \mathrm{~kg} / \mathrm{m}^{2}$. In the control group, there were 20 males and 15 females, aged $3-14$ years old, with an average age of $6.92 \pm 1.91$ years old, and a BMI of $15-26 \mathrm{~kg} / \mathrm{m}^{2}$, with an average BMI of $21.19 \pm 3.46 \mathrm{~kg} / \mathrm{m}^{2}$. The differences in gender, age, BMI, and other general characteristics of patients in the two groups were not statistically significant $(\mathrm{P}>0.05)$. All procedures performed in this study involving human participants were in accordance with the Declaration of Helsinki (as revised in 2013). The study was approved by the Research Ethics Committee of Zaozhuang Municipal Hospital (ZZSLLL008-2016) and informed consent was obtained from all patients and their family members.

\section{Treatment methods}

Children in the control group received conventional treatment, primarily including the use of antibiotics, low tidal volume mechanical ventilation, blood transfusion, and nutritional support. Children in the study group were treated with a lung recruitment strategy on the basis of the control group. The specific method was as follows: the positive end-expiratory pressure (PEEP) incremental method was used once every eight hours. In the initial 
Table 1 Comparison of blood gas index changes before and after treatment

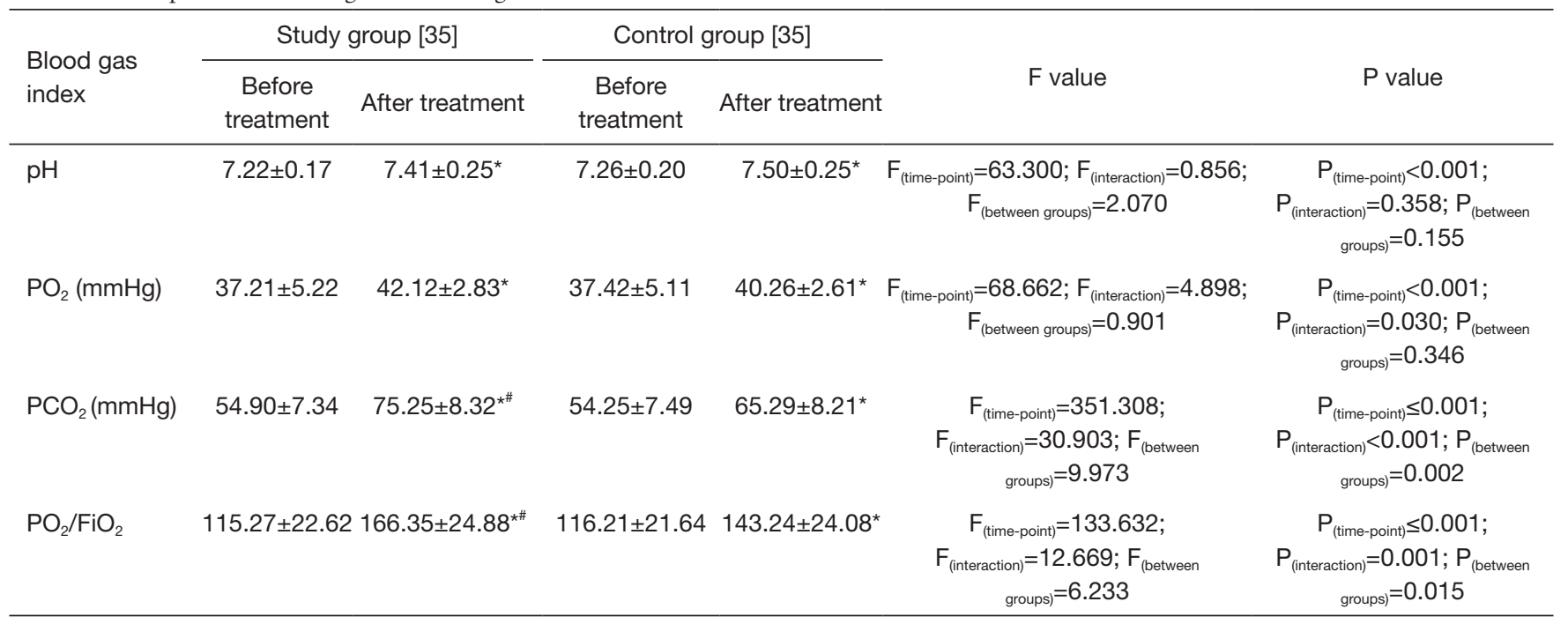

*, $\mathrm{P}<0.05$, compared with the result before treatment; " $\mathrm{P}<0.05$, compared with control group; $\mathrm{PO}_{2}$, partial pressure of oxygen; $\mathrm{PCO}$, partial pressure of carbon dioxide; $\mathrm{PO}_{2} / \mathrm{FiO}_{2}$, partial pressure of oxygen/fraction of inspired oxygen.

pressure control ventilation mode, PEEP was started at $5 \mathrm{cmH}_{2} \mathrm{O}$, and increased by $2 \mathrm{cmH}_{2} \mathrm{O}$ every 5 minutes until it reached $12 \mathrm{mH}_{2} \mathrm{O}$. After maintaining for $30 \mathrm{~s}$, it was gradually decreased to $5 \mathrm{cmH}_{2} \mathrm{O}$ following the previous steps. At this stage, the fraction of inspired oxygen $\left(\mathrm{FiO}_{2}\right)$ was $100 \%$, and blood pressure, heart rate (HR), and other indicators were monitored every 5 minutes.

During the treatment, if the child's blood oxygen saturation was below $85 \%$, blood pressure dropped to $<60 \mathrm{mmHg}$, HR slowed to below 60 beats/min or exceeded 160 beats/min, the treatment was immediately stopped (6).

\section{Observation indicators}

(I) Rehabilitation indicators were detected by comparing the total ventilator use time, intensive care unit (ICU) stay time, and hospital stay time of the two groups after treatment. (II) Blood gas indexes included the partial pressure of oxygen $\left(\mathrm{PO}_{2}\right)$, partial pressure of carbon dioxide $\left(\mathrm{PCO}_{2}\right)$, $\mathrm{PO}_{2} / \mathrm{FiO}_{2}$, and pondus Hydrogenii (pH). (III) Hemodynamic indicators included cardiac output (CO), HR, mean arterial pressure (MAP), and central venous pressure (CVP) were monitored using multi - function monitor. (IV) Lung compliance of the two groups of children was tested before and immediately after recruitment, as well as at 10 and 60 minutes of recruitment using the balloon catheter pressure measuring system.

\section{Statistical analysis}

Data were analyzed using the SPSS22.0 software package (IBM, New York, USA). The normal measurement data were expressed as mean \pm standard deviation $\left(\bar{x}_{ \pm \mathrm{S}}\right)$, and the repeated measurement data was analyzed by repetitive measurement variance analysis. Pairwise comparisons were performed by the least significant difference (LSD)$t$-test, and the difference between single measurement data was examined by $t$-test of independent samples. The count data was expressed as $\mathrm{n}(\%)$, and differences between groups were compared using Fisher's exact test $(\mathrm{n}<40)$. Results with $\mathrm{P}<0.05$ were considered to be significantly different.

\section{Results}

\section{Comparison of blood gas index changes in the two groups before and after treatment}

The results showed that, before treatment, the differences in $\mathrm{pH}, \mathrm{PO}_{2}, \mathrm{PCO}_{2}$, and $\mathrm{PO}_{2} / \mathrm{FiO}_{2}$ levels between the two groups were not statistically significant $(\mathrm{P}>0.05)$. However, after treatment, there were notable differences in blood gas indexes between the two groups $(\mathrm{P}<0.05)$, and the $\mathrm{PO}_{2}, \mathrm{PCO}_{2}$, and $\mathrm{PO}_{2} / \mathrm{FiO}_{2}$ levels of the study group were markedly higher than those of the control group $(\mathrm{P}<0.05$, Table 1). 
Table 2 Comparison of hemodynamic index changes in the two groups before and after treatment

\begin{tabular}{|c|c|c|c|c|c|c|}
\hline $\begin{array}{l}\text { Hemodynamic } \\
\text { index }\end{array}$ & \multicolumn{2}{|c|}{ Study group [35] } & \multicolumn{2}{|c|}{ Control group [35] } & $\mathrm{F}$ value & $P$ value \\
\hline $\mathrm{CO}(\mathrm{L} / \mathrm{min})$ & $7.13 \pm 1.29$ & $6.28 \pm 1.43^{*}$ & $7.32 \pm 1.50$ & $6.95 \pm 1.07^{\star}$ & $\begin{array}{l}F_{(\text {time-point) }}=17.339 ; \\
F_{(\text {interaction) }}=2.684 ; \\
F_{(\text {between groups) }}=2.311\end{array}$ & $\begin{array}{l}P_{\text {(time-point) }}<0.001 ; \\
P_{\text {(interaction) }}=0.106 ; \\
P_{\text {(between groups) }}=0.133\end{array}$ \\
\hline HR (beats/min) & $108.34 \pm 12.15$ & $109.26 \pm 11.87$ & $107.97 \pm 11.86$ & $108.89 \pm 11.59$ & $\begin{array}{l}\mathrm{F}_{\text {(time-point) }}=0.351 ; \\
\mathrm{F}_{\text {(interaction) }}=0.000 ; \\
\mathrm{F}_{\text {(between groups) }}=0.024\end{array}$ & $\begin{array}{l}P_{\text {(time-point) }}=0.555 ; \\
P_{\text {(interaction) }}=1.000 ; \\
P_{(\text {between groups) }}=0.876\end{array}$ \\
\hline MAP $(\mathrm{mmHg})$ & $85.34 \pm 8.37$ & $86.35 \pm 7.34$ & $85.82 \pm 8.21$ & $86.12 \pm 7.81$ & $\begin{array}{l}\mathrm{F}_{(\text {time-point) }}=0.718 ; \\
\mathrm{F}_{\text {(interaction) }}=0.211 ; \\
\mathrm{F}_{\text {(between groups) }}=0.005\end{array}$ & $\begin{array}{l}P_{\text {(time-point) }}=0.400 ; \\
P_{\text {(interaction) }}=0.647 ; \\
P_{\text {(between groups) }}=0.943\end{array}$ \\
\hline CVP (mmHg) & $11.43 \pm 2.68$ & $12.33 \pm 1.86^{\star}$ & $11.68 \pm 2.37$ & $12.13 \pm 1.88^{*}$ & $\begin{array}{l}\mathrm{F}_{\text {(time-point) }}=7.099 ; \\
\mathrm{F}_{\text {(interaction) }}=0.789 ; \\
\mathrm{F}_{\text {(between groups) }}=0.003\end{array}$ & $\begin{array}{l}P_{\text {(time-point) }}=0.010 ; \\
P_{\text {(interaction) }}=0.378 ; \\
P_{(\text {between groups) }}=0.958\end{array}$ \\
\hline
\end{tabular}

*, $\mathrm{P}<0.05$, compared with before treatment; $\mathrm{CO}$, cardiac output; HR, heart rate; MAP, mean arterial pressure; CVP, central venous pressure.

Table 3 Comparison of lung compliance in the two groups before and after treatment $\left(\mathrm{mL} / \mathrm{cmH}_{2} \mathrm{O}\right)$

\begin{tabular}{lcccc}
\hline Lung compliance & Study group [35] & Control group [35] & F value & $P$ value \\
\hline Before recruitment & $25.23 \pm 4.25$ & $24.96 \pm 4.17$ & $F_{\text {(time-point) }}=391.344 ;$ & $P_{\text {(time-point) }}=0.000<0.001 ;$ \\
Immediate recruitment & $30.18 \pm 4.06^{*(1)}$ & $27.36 \pm 4.12^{(1)}$ & $F_{\text {(interaction) }}=20.643 ;$ & $P_{\text {(interaction) }}=0.000<0.001 ;$ \\
Recruitment for 10min & $33.50 \pm 4.81^{*(1) 2(2)}$ & $29.61 \pm 4.31^{(1)(2)}$ & $F_{(\text {between groups) }}=10.064$ & $P_{(\text {between groups) }}=0.002$ \\
Recruitment for 60min & $36.75 \pm 5.73^{*(1)(3)}$ & $32.12 \pm 5.08^{(1)(2)(3)}$ & & \\
\hline
\end{tabular}

*, $\mathrm{P}<0.05$, compared with the control group; ${ }^{1}, \mathrm{P}<0.05$, compared with before immediate lung recruitment; ${ }^{2}, \mathrm{P}<0.05$, compared with immediate lung recruitment; ${ }^{3}, \mathrm{P}<0.05$ was compared with lung recruitment of $10 \mathrm{~min}$.

\section{Comparison of changes in bemodynamic indexes in the two groups before and after treatment}

The results demonstrated that, before treatment, the differences in CO, HR, MAP, and CVP levels between the two groups were not statistically significant $(\mathrm{P}>0.05)$. Similarly, after lung recruitment, there were no marked differences in these indicators between the study group and the control group $(\mathrm{P}>0.05$, Table 2).

\section{Comparison of lung compliance before and after treatment in the two groups}

The results showed that the lung compliance of the two groups continued to increase at different time points after treatment $(\mathrm{P}<0.05)$, and the lung compliance of the study group was higher than that of the control group immediately after recruitment, as well as at 10 and $60 \mathrm{~min}$ of lung recruitment $(\mathrm{P}<0.05$, Table 3).

\section{Comparison of main rehabilitation indicators between the two groups after treatment}

The results showed that the ventilator use, ICU stay, and hospital stay times of the study group were shorter than those of the control group $(\mathrm{P}<0.05)$, and the mortality rate was lower than that of the control group $(\mathrm{P}>0.05$, Table 4).

\section{Discussion}

ARDS is a common clinical syndrome and is mainly characterized by hypoxemia. In recent years, the mortality rate in pediatric diseases has been increasing. Relevant studies have pointed out that the onset of this disease is acute and progresses rapidly, and is often accompanied by symptoms such as respiratory distress and chest tightness. In severe cases, it may cause confusion or even death (7). At present, there are many treatment options for patients with septic shock and ARDS, however these therapies do not 
Table 4 Comparison of the key recovery indexes after treatment between the two groups

\begin{tabular}{lcccc}
\hline Key recovery index & Study group [35] & Control group [35] & T/Fisher & P value \\
\hline Ventilator use time (d) & $6.68 \pm 0.99$ & $9.25 \pm 0.84$ & 11.711 & 13.063 \\
ICU stay time (d) & $6.91 \pm 0.79$ & $10.25 \pm 1.29$ & 15.459 & $<0.001$ \\
Hospital stay time (d) & $10.93 \pm 0.81$ & $15.27 \pm 1.45$ & Fisher & 0.188 \\
Mortality rate (\%) & $3(8.57)$ & $8(22.86)$ & & 0.01 \\
\hline
\end{tabular}

IUC, intensive care unit.

offer a reliable curative effect (8).

Numerous studies have shown that the treatment of pediatric ARDS is primarily based on the principle of correcting and improving the injury of the lung, and mechanical ventilation is a common treatment method (6). However, mechanical ventilation may lead to mechanical ventilation-related lung injury during the treatment process, researchers have discovered that it may cause energy barotrauma, which directly leads to lung injury and aggravates the development of the disease. Therefore, lung protective strategies are required to reduce the lung damage. Previous strategy of using low volume of pulmonary alveolar collapse will lead to alveoli to collapse to a degree, while which can be effectively avoided by the use of lung recruitment strategy. Besides, by adding the proper pressure, the reopening of alveolar could be promoted in order to improve the oxygenation and respiratory systems $(9,10)$. Therefore, in order to reduce the influence of ARDS on the dysfunction and respiratory function of children, this study focused on the influence of lung recruitment strategy on the blood gas index, hemodynamics, lung compliance and rehabilitation index of ARDS children.

As mentioned above, ARDS is caused by the disorder of fluid exchange between blood vessels and tissues in the lungs, and is often accompanied by symptoms such as dyspnea and respiratory distress, which seriously endangers the health and lives of children. Indicators such as the $\mathrm{pH}, \mathrm{PO}_{2}, \mathrm{PCO}_{2}$, and $\mathrm{PO}_{2} / \mathrm{FiO}_{2}$ can reflect the respiratory status of the children. $\mathrm{pH}$ is an index that reflects the acidbase condition of the blood, with a $\mathrm{pH}$ of greater than 7.45 indicating alkalemia (11). $\mathrm{PO}_{2}$ refers to the tension of oxygen molecules in the blood. The other indexes can also be used as key indicators to reflect the body's hypoxia, and have important roles in evaluating whether the body is hypoxic as well as the intensity of hypoxia (12). Numerous studies have pointed out that the level of $\mathrm{PO}_{2}$ in children is closely related to respiratory function, with a low $\mathrm{PO}_{2}$ of less than $60 \mathrm{mmHg}$ indicating respiratory failure in children. $\mathrm{PCO}_{2}$ refers to the pressure produced by carbon dioxide $\left(\mathrm{CO}_{2}\right)$ molecules in the blood, which is an objective indicator reflecting lung respiratory function (13). In addition, the $\mathrm{PO}_{2} / \mathrm{FiO}_{2}$ value can effectively reflect the oxygenation status of the patient's body.

In this study, patients were treated with lung recruitment therapy to allow atmospheric oxygen to enter the alveoli through the respiratory tract, diffuse into pulmonary capillaries, and ultimately reach tissue cells, thus completing the respiratory cycle (14). The results of this study showed that the blood gas indexes of children in the two groups continued to rise after treatment, and the $\mathrm{PO}_{2}, \mathrm{PCO}_{2}$, and $\mathrm{PO}_{2} / \mathrm{FiO}_{2}$ levels of the children who underwent lung recruitment therapy were higher than those of the children who received basic therapy. This suggests that lung recruitment can effectively improve the respiratory function and relieve non-epithelial cell damage in children, resulting in improved clinical outcomes for children with ARDS.

According to reports in the literature, lung recruitment therapy for pediatric ARDS may promote the increase of intrathoracic pressure in children, which will cause venous blood reflux and lead to hemodynamic changes (15). In this study, there were no significant changes in HR, MAP, and CVP levels in children after treatment, indicating that lung recruitment therapy can maintain the stability of hemorheology in children with ARDS. It is speculated that the lung protective ventilation strategy of low-tide air volume and pulmonary retention can effectively improve oxygenation response, reduce intrathoracic pressure, and thus stabilize blood flow. Further analysis showed that the lung compliance value continued to increase at different time points after treatment, and the lung compliance of children in the recruitment group was better than that of the routine treatment group. In addition, the ventilator use, ICU stay, and hospital stay times were shorter after treatment for the recruitment group compared to the routine treatment group. Moreover, the mortality rate of children in the recruitment group was also lower than 
that in the routine treatment group. However, although the fatality rate of the study group was low, the difference between the study group and the control group was not significant, which may be caused by the small sample size of the study, therefore the sample size can be enlarged for verification in the further study.

The results of this study suggest that the lung recruitment strategy can promote the recovery of gas flow, lung ventilation function, and has a positive effect on the recruitment of collapsed alveoli as well as the improvement of lung compliance status. Therefore, to a certain extent, the lung recruitment strategy is conducive to the improvement of the curative effect and the reduction of the mortality of children.

In conclusion, the lung recruitment strategy has a significant effect on the treatment of children with ARDS. It can effectively treat and improve the blood gas function and lung compliance of children, and offers positive outcomes for the stability of hemodynamics.

\section{Acknowledgments}

Funding: None.

\section{Footnote}

Reporting Checklist: The authors have completed the CONSORT reporting checklist. Available at http://dx.doi. org/10.21037/tp-20-383

Data Sharing Statement: Available at http://dx.doi. org/10.21037/tp-20-383

Conflicts of Interest: All authors have completed the ICMJE uniform disclosure form (available at http://dx.doi. org/10.21037/tp-20-383). The authors have no conflicts of interest to declare.

Ethical Statement: The authors are accountable for all aspects of the work in ensuring that questions related to the accuracy or integrity of any part of the work are appropriately investigated and resolved. All procedures performed in this study involving human participants were in accordance with the Declaration of Helsinki (as revised in 2013). The study was approved by the Research Ethics Committee of Zaozhuang Municipal Hospital (ZZSLLL008-2016) and informed consent was obtained from all patients and their family members.
Open Access Statement: This is an Open Access article distributed in accordance with the Creative Commons Attribution-NonCommercial-NoDerivs 4.0 International License (CC BY-NC-ND 4.0), which permits the noncommercial replication and distribution of the article with the strict proviso that no changes or edits are made and the original work is properly cited (including links to both the formal publication through the relevant DOI and the license). See: https://creativecommons.org/licenses/by-nc-nd/4.0/.

\section{References}

1. Henderson WR, Chen L, Amato MBP, et al. Fifty Years of Research in ARDS. Respiratory Mechanics in Acute Respiratory Distress Syndrome. Am J Respir Crit Care Med 2017;196:822-33.

2. Wheeler DS, Dewan M, Maxwell A, et al. Staffing and workforce issues in the pediatric intensive care unit. Transl Pediatr 2018;7:275-83.

3. Matthay MA, Zemans RL, Zimmerman GA, et al. Acute respiratory distress syndrome. Nat Rev Dis Primers 2019;5:18.

4. Amado-Rodríguez L, Del Busto C, García-Prieto E, et al. Mechanical ventilation in acute respiratory distress syndrome: The open lung revisited. Med Intensiva 2017;41:550-8.

5. Sweet DG, Carnielli V, Greisen G, et al. European Consensus Guidelines on the Management of Respiratory Distress Syndrome - 2019 Update. Neonatology 2019;115:432-50.

6. Hess DR. Recruitment Maneuvers and PEEP Titration. Respir Care 2015;60:1688-704.

7. Orbegozo D, Rahmania L, Irazabal M, et al. Endocan as an early biomarker of severity in patients with acute respiratory distress syndrome. Ann Intensive Care 2017;7:93.

8. Ward SL, Turpin A, Spicer AC, et al. Long-term pulmonary function and quality of life in children after acute respiratory distress syndrome: a feasibility investigation. Pediatr Crit Care Med 2017;18:e48-e55.

9. Goligher EC, Hodgson CL, Adhikari NKJ, et al. Lung recruitment maneuvers for adult patients with acute respiratory distress syndrome. a systematic review and meta-analysis. Ann Am Thorac Soc 2017;14:S304-11.

10. Hodgson C, Goligher EC, Young ME, et al. Recruitment manoeuvres for adults with acute respiratory distress syndrome receiving mechanical ventilation. Cochrane Database Syst Rev 2016;11:CD006667. 
11. Foy DS, de Morais HA. A Quick Reference on Metabolic Alkalosis. Vet Clin North Am Small Anim Pract 2017;47:197-200.

12. Heyman SN, Khamaisi M, Zorbavel D, et al. Role of hypoxia in renal failure caused by nephrotoxins and hypertonic solutions. Semin Nephrol 2019;39:530-42.

13. Byrne AL, Bennett M, Chatterji R, et al. Peripheral venous and arterial blood gas analysis in adults: are they comparable? A systematic review and meta-analysis.

Cite this article as: Li B, Li D, Huang W, Che Y. Effect of lung recruitment on blood gas index, hemodynamics, lung compliance, and rehabilitation index in children with acute respiratory distress syndrome. Transl Pediatr 2020;9(6):795801. doi: 10.21037/tp-20-383
Respirology 2014;19:168-75.

14. Mann A, Early GL. Acute respiratory distress syndrome. Mo Med 2012;109:371-5.

15. Tonelli AR, Zein J, Adams J, et al. Effects of interventions on survival in acute respiratory distress syndrome: an umbrella review of 159 published randomized trials and 29 meta-analyses. Intensive Care Med 2014;40:769-87.

(English Language Editor: A. Kassem) 